\title{
BMJ Open Equal health at work? Protocol for an observational study of work organisation, workload and musculoskeletal complaints among women and men in grocery retail
}

\author{
Svend Erik Mathiassen (1) , ${ }^{1}$ Malin Bolin, ${ }^{2}$ Gunilla Olofsdotter, ${ }^{2}$ Elin Johansson ${ }^{1}$
}

To cite: Mathiassen SE, Bolin M, Olofsdotter G, et al. Equal health at work? Protocol for an observational study of work organisation, workload and musculoskeletal complaints among women and men in grocery retail. BMJ Open 2020;10:e032409. doi:10.1136/ bmjopen-2019-032409

- Prepublication history for this paper is available online. To view these files, please visit the journal online (http://dx.doi. org/10.1136/bmjopen-2019032409).

Received 17 June 2019 Revised 29 November 2019 Accepted 31 December 2019

A) Check for updates

(C) Author(s) (or their employer(s)) 2020. Re-use permitted under CC BY-NC. No commercial re-use. See rights and permissions. Published by BMJ.

${ }^{1}$ Centre for Musculoskeletal Research, Department of Occupational Health Sciences and Psychology, University of Gävle, Gävle, Sweden

${ }^{2}$ Department of Social Sciences, Mid Sweden University,

Sundsvall, Sweden

Correspondence to Dr Svend Erik Mathiassen; smn@hig.se

\section{ABSTRACT}

Introduction Women generally report more work-related musculoskeletal complaints than men and have higher rates of sickness absence, even within occupations. One likely reason is that work tasks within the occupation are gendered, that is, women and men have different tasks, even when sharing the same job title. Retail is an appealing sector for studying working conditions and work environment in a gender context. The prevalence of work-related complaints is high, physical loads may differ considerably between tasks and the distribution of tasks is likely gendered. The overall aim of this study in retail is to examine factors at the organisational and individual level that may, in a gender perspective, explain working conditions, work tasks, workloads and musculoskeletal health.

Methods and analyses Data will be collected in two grocery stores, each with 50-70 workers, at two occasions interspersed by about 1 year. In each of these four waves, data collection will include a web-based questionnaire to all workers addressing, for example, work tasks, psychosocial factors, fatigue and pain; semistructured interviews with managers and approximately 10 workers addressing, for example, competences and decision levels; and technical measurements of postures, movements and heart rate in about 30 workers. The study is novel in combining an organisational gender perspective addressed through qualitative methods with a quantitative analysis of tasks, workload and health. The design allows an examination of both how genders may differ, and why they may differ, as well as analyses of the extent to which gendered working conditions change over time in the two participating stores.

Ethics and dissemination Approval of the study by the Swedish Ethical Review Authority (reference number 2017/404) has been obtained. This work will be disseminated by publication of peer-reviewed papers in scientific journals, presentations at scientific conferences and in meetings with representatives from Swedish retail, including unions and employers' organisations.

\section{INTRODUCTION}

Gender equality at work, including good health for both women and men, is a major
Strengths and limitations of this study

- This study will combine qualitative and quantitative methods in investigating what differs in the working conditions and work environment of men and women in grocery retail, and why it differs, in the context of gendered attitudes to work.

- The 1-year follow-up design of the study allows an examination of the turnover of workers, as well as possible changes in working conditions, again in the context of gender equality.

- Our results may help the grocery retail sector better understand and, eventually, act on gender inequalities in working conditions and working environment.

- The primary limitation of the study is the limited number of participating stores and workers, which may render results less generalisable across the retail sector at large.

goal in European ${ }^{1}$ and international ${ }^{2}$ agendas promoting social justice and sustainable growth. In industrialised countries, however, women generally suffer from work-related musculoskeletal complaints to a larger extent than men. The difference appears particularly pronounced for complaints in the neck, shoulder and upper extremities ${ }^{3-5}$ and in the legs and feet $^{36}$; while the prevalence of low-back complaints is more similar among women and men. ${ }^{37}$ Some of this sex/gender difference may be associated with conditions at work, while some may be associated with, for example, gendered patterns of behaviour and gendered socioeconomic conditions. Thus, the inequality in occupational health is likely explained by multiple causes, which can be understood in a hierarchical, nested structure (figure 1). ${ }^{8}$

First, in many countries, including Sweden, the labour market is highly segregated, with women and men working, to a large extent, 


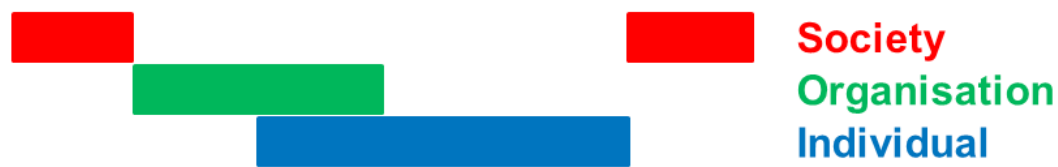

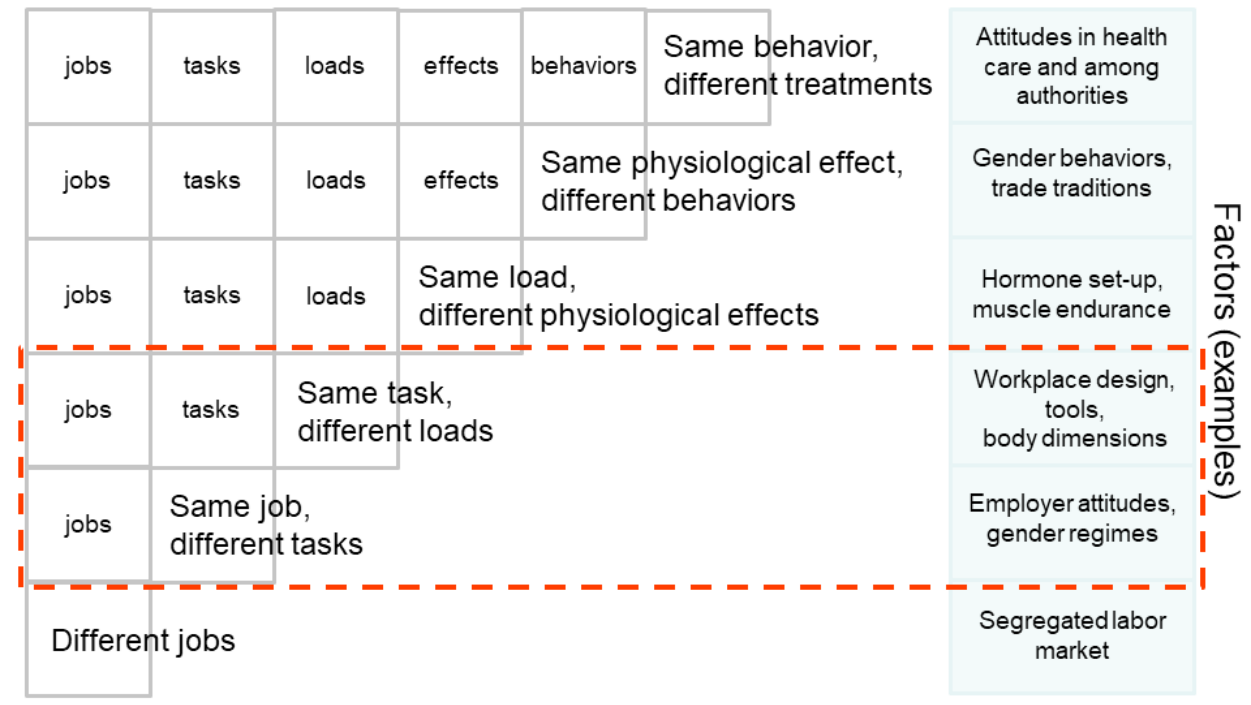

Figure 1 Schematic overview of hierarchical steps at the societal, organisational and individual level, explaining why workrelated musculoskeletal complaints are more prevalent among women than among men. The fact that women and men are unequally represented in different occupational sectors may contribute (step 1). Even if women and men have the same job, they may differ in work tasks (step 2), which can further contribute to women having more musculoskeletal complaints. Women and men performing the same work task may experience different workloads, for instance, owing to gendered design of workplaces and tools, and to differences between women and men in body dimensions and physical capacity (step 3). Although women and men would work at equal loads, they may differ in their physiological response (step 4). On top of that, women and men may have different behaviours once a complaint has emerged (step 5), and they may be treated in different ways, for example, by healthcare providers and public authorities (step 6). Factors outside work may interact with those at work, mainly at steps 3,5 and 6 . The red frame marks the focus of the present study.

in different occupations associated with different occupational risk factors. ${ }^{9}$ Second, even within many occupations, women report more musculoskeletal complaints than men, and also have more diagnosed symptoms. ${ }^{10-13}$ One likely reason is that work tasks within the occupation are often gendered, that is, that women and men have, to a considerable extent, different tasks, even when sharing the same job title. ${ }^{12}{ }^{14-19}$ Work tasks performed by women are often more repetitive, and thus associated with less variation, than tasks performed by men. ${ }^{12}$ 20-22 There are, however, inspiring examples of occupations where women and men appear to perform the same tasks to the same extents, that is, where work is not gendered in this respect. ${ }^{23} \mathrm{~A}$ third explanation to gender differences in work-related musculoskeletal complaints may be that women experience higher physical workloads than men when performing the same task. This could, for instance, be due to workstations and tools being developed to fit the average male anthropometry and performance capacity, ${ }^{18} 24$ even if gendered effects of workstation and tool design are largely unknown. ${ }^{25}$ As a fourth explanation, women may, on average, have different physiologic responses than males to a certain physical work load, ${ }^{26}$ for instance, due to differences in muscle fibre composition, ${ }^{27} 28$ motor control $^{29}$ or pain sensitivity. ${ }^{30}$ However, such biological differences may only to a limited extent be able to explain differences in occupational health outcomes, compared with the effects of gendered work organisation and task exposures mentioned above. This notion is corroborated by the observation that women and men with similar exposures at work appear to report work-related musculoskeletal complaints to the same extent. ${ }^{131}$ Notably, while the model outlined above and illustrated in figure 1 focuses on the influence of work on musculoskeletal complaints, exposures outside work will also contribute in determining the eventual health status. To this end, women may typically engage in unpaid work to a larger extent than men, resulting in larger cumulated exposures. ${ }^{32} 33$

Since occupational health is gendered, successful interventions addressing gender inequality at work have a potential to positively influence both physical and mental health and well-being for the workers, ${ }^{34}$ and thus even the viability of the whole organisation. ${ }^{35}$ In order to increase effectiveness, interventions should be based on evidence regarding gendered work roles and working conditions and their possible consequences in terms of physical workload and psychosocial factors at the level of 
individual workers. ${ }^{36}$ They also need to consider factors at the organisational level that may lead to unequal roles and conditions. Few studies have, so far, addressed division of labour and work roles in an organisation from a gendered perspective, ${ }^{37-39}$ and to our knowledge, no study has combined a gendered analysis with a thorough, evidence-based quantitative evaluation of equality in physical and psychosocial conditions. The retail sector suffers from a high prevalence of work-related musculoskeletal complaints, especially in the arms, shoulders and neck, ${ }^{40-42}$ and a high prevalence of long-term sick leave, at least in Sweden. ${ }^{43}$ In Sweden, the retail sector employs about 500000 individuals, with quite similar proportions of women and men. ${ }^{44}$ A previous Swedish study suggests that physical workloads may differ considerably between different tasks in a grocery store ${ }^{45}$ and studies taking a sociological/etnographical perspective have confirmed a gendered distribution of tasks. ${ }^{38} 46$ Some tasks are considered 'female' and may therefore, because of gendered norms, be excluded from job rotations otherwise intended to lead to more attractive work for everybody. Thus, results from ergonomics as well as sociological research suggest that retail is an appealing sector for studying work tasks, workloads and working conditions in a gender perspective. However, no previous study has combined a thorough assessment of work tasks and workloads in retail with an examination of those gendered attitudes and practices in the organisation that determine work tasks and working conditions for women and men.

Thus, the overall aim of the present 3-year study in retail is to examine factors at the organisational and individual level that may explain working conditions, work tasks, workloads and musculoskeletal health in a gendered perspective. The study will answer the following three specific research questions:

1. To what extent do working conditions, work tasks, physical and psychological workload, and work-related musculoskeletal complaints differ between men and women in grocery stores?

2. To what extent do staffing, work tasks, workloads and the occurrence of musculoskeletal complaints change over time in grocery stores?

3. How do gendered attitudes and practices in the grocery stores influence the observed conditions and their possible change over time?

\section{METHODS AND ANALYSES}

\section{Study design and study population}

Two grocery stores will be recruited to a prospective cohort. Each of the stores will have 50-70 workers, being a trade-off between having a manageable population for collecting extensive data on physical workloads and psychosocial conditions, while at the same time having stores sufficiently large to contain a wide selection of tasks, and to allow an analysis of gendered practices at the organisational level. Based on employment statistics in
Swedish retail, we expect proportions of men and women in the stores to be similar. ${ }^{44}$ The stores will belong to the same corporate group, thus sharing some basic properties with respect to corporate policies and attitudes, and they will, for practical reasons, be located in the middle part of Sweden. Including two stores in the study will allow for a tentative generalisation of findings to grocery stores beyond those investigated. Eligible grocery stores, as identified from records provided by the Swedish Work Environment Authority, will be contacted by email, followed by a telephone call. Among stores declaring an interest in participating, two stores will be selected that fulfil the requirements stated above, including being convenient for logistical reasons. In each of the two selected stores, data will be collected at two occasions interspersed by about 1 year. In the first year of the study, data are collected in store A (A1). In the second year, follow-up data will be collected in store A (A2), closely followed by collection of baseline data in store B (B1). In the third year, follow-up data are collected in store B (B2). All four data collection waves will, to the extent feasible, be performed at the same time of the year, and not during atypical periods, such as Christmas rush or summer holidays. Comparisons of results at $\mathrm{A} 1$ with $\mathrm{A} 2$, and at $\mathrm{B} 1$ with $\mathrm{B} 2$ allow examination of the stability of findings over time, as well as of possible organisational changes during the year of follow-up, and their effects. At each occasion, data are collected with both qualitative and quantitative methods, including a web-based questionnaire to all workers, then semistructured interviews with managers and approximately 10 workers, and then technical measurements of physical workload in approximately 30 workers. Participants in interviews will be selected based on the work tasks they predominantly perform. Likewise, workers will be recruited to the technical measurements so as to represent all work tasks in the store. Any specific worker may, thus, participate in both the questionnaire, interview and direct measurement parts of the data collection. Workers will receive verbal and written information about the study, and written informed consent will be obtained from all participants prior to data collection.

\section{Data collection}

Organisational variables

Prior to data collection, all work tasks performed at the store will be identified in consultation with the store manager (eg, working with charcuterie; with fruit and vegetables; with dairy products; at the counter; in the office). We expect this list to consist of approximately 10 tasks.

Individual interviews and focus group interviews will be conducted with the store managers, chiefs of staff and managers responsible for various organisational units in the store, to map how the organisation is formally organised and staffed. The interviews, conducted by the authors $\mathrm{MB}$ and GO, both $\mathrm{PhD}$ and female, will include questions about sections and levels of decisions, management and delegations of staff liability, staff composition, competence 
structure, segregation by gender or ethnicity within the organisation, supply of resources, level of technology, strategies for flexibility, systems for control and follow-up of the organisation and organisational changes. ${ }^{47}$ Neither MB nor GO has any prior relationship with the studied organisations or interviewed participants. The interviews, lasting about 1 hour, will be conducted and audio recorded in a separate room with only the researchers and participant(s) present, fully transcribed and analysed subsequently. At follow-up, a particular emphasis will be given to documenting the managers' opinions about changes of these different aspects compared with baseline. Both MB and GO have a long-standing experience in conducting qualitative research based on interviews in occupational settings.

\section{Perceived work roles, working conditions and workload}

All workers will be encouraged to answer a web-based questionnaire containing items addressing demographic variables, including age, sex, country of birth and level of education; as well as general issues related to work, such as number of years in the occupation and in this particular grocery store. The questionnaire will also address time spent in different tasks, on basis of the list of tasks identified together with the manager, as well as perceived physical and mental exertion associated with each task and during work at large. A further part of the questionnaire addresses psychosocial conditions, using questions from the Copenhagen Psychosocial Questionnaire. ${ }^{48}$ Finally, the questionnaire contains items dealing with musculoskeletal complaints in various body regions. ${ }^{49}$ We have used similar questionnaires in previous field studies. ${ }^{50} 51$ If possible, the workers will be offered to answer the questionnaire during the working hours.

Approximately 10 workers representing all work tasks in the stores will be asked to participate in focus group interviews, aiming at obtaining a deeper insight into work roles, working conditions, work environment and work/non-work interference. Furthermore, semistructured individual interviews will be conducted with store managers and others having managing assignments in the two stores. The exact number of interviews depends on the organisation of each specific store. The interviews will follow a guide developed by the researchers on basis of Acker's theoretical concepts (see Data processing and analysis). These focus group and individual interviews will be recorded, fully transcribed and analysed subsequently. At follow-up, questions will be added, addressing perceived changes during the preceding year, that is, since baseline.

\section{Work tasks and physical workload}

A sample of about 30 workers representing all work tasks in the store will be asked to participate in measurements of physical workload for three full days each.

Postures and movements of the dominant upper arm, as well as gross body postures and physical activities, will be assessed using three-axial accelerometers (Axivity
AX3, Axivity, Newcastle upon Tyne, UK). The accelerometer has a size of $23 \times 32.5 \times 7.6 \mathrm{~mm}$ and weights $11 \mathrm{~g}$. One accelerometer is attached using double-coated adhesive tape on the dominant upper arm at the insertion of the deltoid tendon, the x-axis pointing downwards, and covered with a plastic adhesive film (Opsite Flexifix, Smith \& Nephew, London, UK). The second accelerometer will be attached on the thigh, midways between the patella and the hip joint. Workers who are allergic to adhesive tape or are pregnant will not be allowed into the technical measurements. The two accelerometers are initialised in synchrony, and collect data at $25 \mathrm{~Hz}$. The accelerometers are initialised and data downloaded using OmGui (V.1.0.0.30; Open Movement, Newcastle University, UK).

Heart rate and heart rate variability (HRV) will be assessed as objective measures of metabolic load and autonomic regulation (stress level), respectively. ${ }^{52}$ Participants will wear a Bodyguard2 heart rate monitor (Firstbeat Bodyguard; Firstbeat Technologies, Jyväskylä, Finland) continuously during the three measurement days, collecting signals from ECG electrodes (Ambu, Ballerup, Denmark) attached on cleansed and, if necessary, shaved skin. The monitor is initialised using the Firstbeat SPORTS uploader (V.1.0; Firstbeat Technologies). The Bodyguard2 monitor also contains an accelerometer, which enables synchronisation with other data sources as described below.

The accelerometers and the heart rate monitor will be attached by a member of the research team at the beginning of the work shift on day 1 , and removed when the shift ends on day 3 . At the beginning of the measurement period, and at the beginning of the video recordings (see next paragraph), the participant performs a jump, followed by $10 \mathrm{~s}$ of standing still, and then a second jump. This procedure enables synchronisation of recordings by accelerometers, heart rate monitor and video.

During the second or third day of measurement, a member of the research team will videotape the worker continuously for about 4 hours using a handheld camera (HDR-CX450, Sony); to the extent possible at an angle perpendicular to the worker. ${ }^{53}$

During all three measurement days, the participants will be requested to keep a diary on working hours, work tasks and pauses/breaks. The participant notes the clock time at every change in work task and every break.

\section{Data processing and analysis}

The semistructured interviews and focus group interviews will be analysed using Acker's theory about inequality regimens. ${ }^{54}$ Acker states that inequality regimens exist in all organisations and can be defined as loosely interrelated practices, processes, actions and meanings' that create power orders from intersections of class, gender and ethnicity within the organisation. This theory comprises both the organisational and the individual level, and is used as a framework for analysing how complex inequalities are produced and reproduced 
within organisations. ${ }^{54-56}$ Distribution of work tasks between workers, their opportunities to be promoted, employment security, benefits and salary, control and compliance are examples of such practices. The individual interviews and focus group interviews are analysed using a thematic method, identifying patterns and deviations through repeated readings of the transcript interviews. ${ }^{57}$ All data will be coded in several steps, ${ }^{58} 59$ and sorted into matrices based on the theoretical concepts of inequality regimens. ${ }^{54}$

After identification and elimination of non-wear periods and corrupted data, accelerometer data will be analysed using the Acti4 software, ${ }^{60}$ which has shown an excellent validity in identifying sitting, standing, walking and more vigorous activities from the thigh accelerometer data, as well as arm elevation angles from the arm accelerometer data. ${ }^{61} 62$ The occurrence of sitting, standing, walking and more vigorous activities will be expressed in terms of minutes/day as well as percentages; arm elevation will be reported using a comprehensive set of variables used in several previous studies. ${ }^{63-65}$ Since data describing parts of a whole (eg, percentage of time spent in different activities) are inherently constrained and interdependent, such variables will be processed and analysed using a Compositional Data Analysis approach. ${ }^{66}$

The Firstbeat SPORTS uploader (V.1.0; Firstbeat Technologies) will be used for downloading and visually inspecting the ECG data for artefacts, which will be removed. HRV variables will be extracted in both time and frequency domains, so as to assess activity in the autonomic nervous system. ${ }^{52}$

All data will then be imported to the Spike2 software (V.7.03, Cambridge Electronic Design, Cambridge, UK), allowing visual inspection on a timeline of data from all sources in parallel. To enable synchronisation of the accelerometer and ECG data, the reference sequence will be identified in the accelerometer file. The video recordings will be synchronised with the instrumental measurements by identifying the reference sequence in the beginning of the video film. The video material will be observed in Spike2, noting the work task as well as occurrences of lifts of items $\geq 1 \mathrm{~kg}$, periods of kneeling and squatting, and periods of pushing/pulling, that is, important physical workloads that the accelerometers will not detect. Information from the diary on self-reported periods in different work tasks will be added to the synchronised timeline of observed and recorded data, and compared with the objective recordings in order to estimate the ability of the workers to correctly register breaks and changes between work tasks.

For each worker, exposure data will be obtained for the work as a total (overall job exposure), as well as for individual tasks as identified from the video. If a work task is performed more than once, recordings are concatenated. A 'task exposure matrix ${ }^{23}$ 67-69 will be constructed, stratified by gender to the extent possible, showing workloads expressed in terms of group mean and variance between and within worker for each task. ${ }^{23}$
In the context of research question 1, the interviews with managers and staff will give insight into the working conditions for women and men, complementing data obtained from the questionnaires. The task exposure matrix will give information about physical workloads for women and men in each individual task and, when combined with data from the diary and the questionnaire, for the overall job of each individual worker. Gender differences in physical workload, psychosocial conditions and musculoskeletal complaints will be examined on the basis of standard descriptive statistics and effect sizes as described in the Statistical considerations section.

Research question 2 will be addressed by comparing baseline and follow-up data using metrics describing effect sizes (see below), and by examining the extent to which managers and staff report changes over time in the interviews.

Research question 3 will be addressed by analysing individual and focus group interviews specifically in the context of disclosing possible gendered attitudes and practices that may contribute to inequality in working conditions, work tasks, physical and psychological workload and work-related musculoskeletal complaints.

\section{Statistical considerations}

Most previous studies documenting working conditions, workload and musculoskeletal complaints using quantitative methods, such as questionnaires and technical measurements, have based their data analyses, including a priori power calculations, on standard statistical methods assuming that participants constitute a sample from an, in principle, unlimited population of workers in similar settings. When reporting results at the level of a store in the present study, the notion of an unlimited target population is less relevant, since staff is of limited size, expectedly 50-70 workers. Thus, when analysing results specifically for a particular store, each worker should be regarded as a representative for his/her organisation, and not for all workers employed in retail. In the present study, this notion will be acknowledged by adapting basic descriptive statistics, such as SDs, to accommodate populations of limited size, using a so-called finite population correction. ${ }^{70}$ Notably, statistical performance will be better with limited-size populations than with populations that are asymptotically unlimited in size. Sample sizes needed to obtain a certain precision of the estimated group mean will be smaller, and power at a certain sample size will be better. Based on previous studies on exposure variability within and between workers, ${ }^{63-65}$ and given this finite population interpretation, we regard 30 individuals in each grocery store (ie, half of the workers) to be a sufficient sample to give reliable quantitative data on exposures in the store.

Also, following a strong tradition in research, conclusions regarding the significance of obtained results have most often been based on inspection of $p$ values vis-a-vis a predetermined threshold. ${ }^{72}$ In the context of reporting and interpreting our results, that is, data describing task 
exposures and overall differences between women and men, we emphasise that the study is descriptive and observational, and does not pursue any specific hypotheses, for example, on the size and direction of gender differences. This is reflected in the formulation of the two first research questions, asking to what extent results differ by gender and time. In keeping with recent statistical literature, ${ }^{72}{ }^{73}$ we find that such questions are the best answered using metrics describing absolute and relative effect sizes. ${ }^{74}$ Therefore, we will use standard descriptive statistics (mean values with 95\% CIs) to describe exposures in individual tasks and job(s), stratified by gender, and we will report differences between tasks and between genders in terms of effect sizes with 95\% CIs. Among several possible metrics of effect size, ${ }^{74}$ we find that the eta-squared, $\eta^{2}$, (or, equivalently, the contrast ${ }^{69}$ ) will suit our purposes best. On a scale from 0 to $1, \eta^{2}$ measures to which extent observed differences between two or more groups, such as genders or tasks, can be explained by 'true' membership of the groups, as opposed to being caused by variability within groups. CIs for descriptive statistics and effect sizes will be estimated using bootstrapping, which is an established approach in our group. ${ }^{6975-77}$ We will, eventually, compare our results with reports in the literature of similar metrics, ${ }^{78}$ or of data allowing for estimation of those metrics. ${ }^{23}$

\section{Advisory committee}

The study will be supervised by an advisory committee containing representatives from the central trade union within retail and from the retail employers' central organisation, as well as from the Swedish Work Environment Authority and the scientific community. The advisory committee serves as an arena for discussing issues of relevance to the implementation of the study, for example, recruitment of grocery stores, and it will contribute to the interpretation of results in a practical context. To this end, the advisory committee will offer an eventual channel for disseminating experiences and results to the retail sector in general, beyond the feedback offered by the researchers to the participating stores and workers.

\section{Patient and public involvement}

The study does not address any clinical questions. Involvement of patients in any phase of the study is therefore not an issue. We will not involve the public in any part of the study either. Study participants will receive information about the results of the study on staff meetings in the shops. Workers participating in the technical measurements of postures, movements and heart rate will receive personalised reports summarising their own results.

\section{Strengths and limitations}

A major novelty of the present study is the approach of combining an organisational perspective on gender, using established techniques from gender research, with a quantitative analysis of the consequences of gendered processes for the individual worker in terms of tasks, workload and musculoskeletal complaints. Some previous studies in retail as well as in other occupational sectors have been devoted to gendered work at an organisational level, and many studies, some even in retail, have addressed physical workloads and psychosocial conditions at the level of individual workers, but to our knowledge the present study is the first to offer a combination. This design allows an examination of both how genders may differ, and why they may differ. Also, in having a longitudinal design, the study allows analyses of the extent to which gendered working conditions change over time in the two participating stores.

The retail sector in Sweden employs approximately equal proportions of women and men, and the prevalence of work-related complaints is large compared with the Swedish average, especially among women. ${ }^{43}$ Therefore, retail is a suitable sector for the study of jobs, working conditions and workload from a gender perspective. Also, retail offers a variety of work tasks of different complexity and, likely, different physical and mental workloads, ${ }^{51}$ which renders questions addressing health effects of gendered distributions of work relevant. We regard grocery stores with $50-70$ workers to be of a suitable size, that is, sufficiently large to employ women and men in numbers allowing conclusions at the organisational level, and to show a likely diversity of work tasks, while at the same time being so small that a thorough documentation of organisational and individual factors is feasible. It is reasonable to assume that about 30 workers in each store will agree to participate in measurements of physical workload and that 10 will agree to take part in focus group interviews; as stated above, these sample sizes are expected to allow trustworthy answers to the research questions.

At the same time, the primary limitation of the study is the limited number of stores, and thus, workers, which will limit the generalisability of the eventual results. However, we believe that the selection of two similar stores, in terms of, for example, superior corporate group policy, geographical location and size, allows for some generalisability, at least to the corporate group, but hopefully even to the food retail sector at large, at least as inspiring case studies of gender equality.

\section{Dissemination and significance}

We will disseminate this work by publication of peerreviewed papers in scientific journals, reporting the results in accordance with the Strengthening the Reporting of Observational Studies in Epidemiology guidelines for observational studies, to the extent relevant to the study design. We will also present the study at scientific conferences. Data will be shared with eligible colleagues through established channels; for others, data will be available from the project PI (Svend Erik Mathiassen) on reasonable request. Outside the scientific community, results will be disseminated in reports from the Swedish Work Environment Authority, and we will 
present results and experiences at meetings with representatives from Swedish trade, including unions and employers' organisations.

We hope that our study, even if involving only two stores, can disclose gendered mechanisms that will inspire the food retail sector at large to reconsider equality, and thus, eventually, reach a sustainable work life for both women and men employed in retail. Notably, jobs, working conditions and workload can be changed from within the organisation, as opposed to other factors determining equality in health, such as gender segregation on the labour market. Results from the study may also support the Swedish Work Environment Authority, which funds the study, in tailoring inspections in the retail sector to emphasise a gender perspective. In a wider perspective, we hope that results from the study can feed a general awareness of factors contributing in explaining gender inequality in work-related health.

Contributors SEM conceived of the study and designed it together with MB and GO. EJ contributed in planning of the data collection. EJ and SEM drafted the manuscript and MB and GO revised it critically. All authors have read and approved the manuscript in its present form.

Funding This work was supported by the Swedish Work Environment Authority, grant number 2015/033753-85.

Disclaimer The funding body reviewed and approved the study but has no further role in study design, data collection, data analysis or outputs from the study.

Competing interests None declared.

Patient consent for publication Not required.

Ethics approval The study has been approved by the Regional Ethical Review Board in Uppsala, Sweden (2017/404).

Provenance and peer review Not commissioned; externally peer reviewed.

Open access This is an open access article distributed in accordance with the Creative Commons Attribution Non Commercial (CC BY-NC 4.0) license, which permits others to distribute, remix, adapt, build upon this work non-commercially, and license their derivative works on different terms, provided the original work is properly cited, appropriate credit is given, any changes made indicated, and the use is non-commercial. See: http://creativecommons.org/licenses/by-nc/4.0/.

ORCID iD

Svend Erik Mathiassen http://orcid.org/0000-0003-1443-6211

\section{REFERENCES}

1 European Commission. The European Pillar of social rights in 20 principles. Brussels: European Commission, 2019. https://ec.europa. eu/commission/priorities/deeper-and-fairer-economic-and-monetaryunion/european-pillar-social-rights/european-pillar-social-rights-20principles_en\#chapter-i-equal-opportunities-and-access-to-thelabour-market

2 United Nations. The sustainable development agenda, 2015. Available: https://www.un.org/sustainabledevelopment/developmentagenda/

3 Swedish Work Environment Authority. Work-Related Disorders 2018. Arbetsmiljöstatistik Rapport 2018:3 (in Swedish, with summary in English. Stockholm: Swedish Work Environment Authority, 2018.

4 Treaster DE, Burr D. Gender differences in prevalence of upper extremity musculoskeletal disorders. Ergonomics 2004;47:495-526.

5 Wahlstedt K, Norbäck D, Wieslander G, et al. Psychosocial and ergonomic factors, and their relation to musculoskeletal complaints in the Swedish workforce. Int J Occup Saf Ergon 2010;16:311-21.

6 Messing K, Tissot F, Stock S. Distal lower-extremity pain and work postures in the Quebec population. Am J Public Health 2008;98:705-13.

7 Leboeuf-Yde C, Nielsen J, Kyvik KO, et al. Pain in the lumbar, thoracic or cervical regions: do age and gender matter? a population-based study of 34,902 Danish twins 20-71 years of age. BMC Musculoskelet Disord 2009;10:39.

8 Lewis C, Mathiassen SE. Physical work, gender, and health in working life. State of knowledge report 2013:9. Stockholm: Swedish Work Environment Authority, 2013.

9 Eurofound. Sixth European working conditions survey - overview report. Luxembourg, 2016.

10 Nordander C, Hansson Gert-Åke, Ohlsson K, et al. Exposureresponse relationships for work-related neck and shoulder musculoskeletal disorders - Analyses of pooled uniform data sets. Appl Ergon 2016;55:70-84.

11 Nordander C, Ohlsson K, Åkesson I, et al. Exposure-response relationships in work-related musculoskeletal disorders in elbows and hands - A synthesis of group-level data on exposure and response obtained using uniform methods of data collection. Appl Ergon 2013;44:241-53.

12 Karlqvist L, Tornqvist EW, Hagberg M, et al. Self-Reported working conditions of VDU operators and associations with musculoskeletal symptoms: a cross-sectional study focussing on gender differences. Int J Ind Ergon 2002;30:277-94.

13 Mergler D, Brabant C, Vézina N, et al. The weaker sex? men in women's working conditions report similar health symptoms. $J$ Occup Med 1987;29:417-21.

14 Nordander C, Ohlsson K, Åkesson I, et al. Risk of musculoskeletal disorders among females and males in repetitive/constrained work. Ergonomics 2009;52:1226-39.

15 Nordander C, Ohlsson K, Balogh I, et al. Fish processing work: the impact of two sex dependent exposure profiles on musculoskeletal health. Occup Environ Med 1999;56:256-64.

16 Messing K, Dumais L, Courville J, et al. Evaluation of exposure data from men and women with the same job title. J Occup Med 1994;36:913-7.

17 Calvet B, Riel J, Couture V, et al. Work organisation and gender among hospital cleaners in Quebec after the merger of 'light' and 'heavy' work classifications. Ergonomics 2012;55:160-72.

18 Messing K, Tissot F, Saurel-Cubizolles MJ, et al. Sex as a variable can be a surrogate for some working conditions: factors associated with sickness absence. J Occup Environ Med 1998;40:250-60.

19 Messing K, Chatigny C, Courville J. 'Light' and 'heavy' work in the housekeeping service of a hospital. Appl Ergon 1998;29:451-9.

20 Eng A, 't Mannetje A, McLean D, et al. Gender differences in occupational exposure patterns. Occup Environ Med 2011;68:888-94.

21 Fransson-Hall C, Byström S, Kilbom A. Self-Reported physical exposure and musculoskeletal symptoms of the forearm-hand among automobile assembly-line workers. J Occup Environ Med 1995;37:1136-44.

22 Hooftman WE, van der Beek AJ, Bongers PM, et al. Gender differences in self-reported physical and psychosocial exposures in jobs with both female and male workers. J Occup Environ Med 2005;47:244-52.

23 Heilskov-Hansen T, Svendsen SW, Frølund Thomsen J, et al. Sex differences in task distribution and task exposures among Danish house painters: an observational study combining questionnaire data with biomechanical measurements. PLoS One 2014;9:e110899.

24 Leijon O, Bernmark E, Karlqvist L, et al. Awkward work postures: association with occupational gender segregation. Am J Ind Med 2005;47:381-93.

25 Hooftman WE, van der Beek AJ, van de Wal BG, et al. Equal task, equal exposure? are men and women with the same tasks equally exposed to Awkward working postures? Ergonomics 2009;52:1079-86.

26 Côté JN. A critical review on physical factors and functional characteristics that may explain a sex/gender difference in workrelated neck/shoulder disorders. Ergonomics 2012;55:173-82.

27 Lindman R, Eriksson A, Thornell LE. Fiber type composition of the human male trapezius muscle: enzyme-histochemical characteristics. Am J Anat 1990;189:236-44.

28 Lindman R, Eriksson A, Thornell LE. Fiber type composition of the human female trapezius muscle: enzyme-histochemical characteristics. Am J Anat 1991;190:385-92.

29 Srinivasan D, Sinden KE, Mathiassen SE, et al. Gender differences in fatigability and muscle activity responses to a short-cycle repetitive task. Eur J Appl Physiol 2016;116:2357-65.

30 Racine M, Tousignant-Laflamme Y, Kloda LA, et al. A systematic literature review of 10 years of research on sex/gender and experimental pain perception - part 1: are there really differences between women and men? Pain 2012;153:602-18.

31 Coury HJCG, Porcatti IA, Alem MER, et al. Influence of gender on work-related musculoskeletal disorders in repetitive tasks. Int $J$ Ind Ergon 2002;29:33-9. 
32 Lundberg U. Psychophysiology of work: stress, gender, endocrine response, and work-related upper extremity disorders. Am J Ind Med 2002;41:383-92.

33 Floderus B, Hagman M, Aronsson G, et al. Work status, work hours and health in women with and without children. Occup Environ Med 2009;66:704-10.

34 Elwér S, Harryson L, Bolin M, et al. Patterns of gender equality at workplaces and psychological distress. PLoS One 2013;8:e53246.

35 Dul J, Neumann WP. Ergonomics contributions to company strategies. Appl Ergon 2009;40:745-52.

36 van der Beek AJ, Dennerlein JT, Huysmans MA, et al. A research framework for the development and implementation of interventions preventing work-related musculoskeletal disorders. Scand J Work Environ Health 2017;43:526-39.

37 Abrahamsson L. Restoring the order: gender segregation as an obstacle to organisational development. Appl Ergon 2002;33:549-57.

38 Johansson K, Fältholm Y, Abrahamsson L. Job rotation meets gendered and routine work in Swedish supermarkets. NORA 2015;23:109-24.

39 Tolich M, Briar C. Just checking it out: exploring the significance of informal gender divisions amongst American supermarket employees. Gender, Work Organ 1999;6:129-33.

40 Sansone V, Bonora C, Boria $\mathrm{P}$, et al. Women performing repetitive work: is there a difference in the prevalence of shoulder pain and pathology in supermarket cashiers compared to the general female population? Int J Occup Med Environ Health 2014;27:722-35.

41 Forcier L, Lapointe C, Lortie M, et al. Supermarket workers: their work and their health, particularly their self-reported musculoskeletal problems and compensable injuries. Work 2008;30:493-510.

42 Lundberg U, Dohns IE, Melin B, et al. Psychophysiological stress responses, muscle tension, and neck and shoulder pain among supermarket cashiers. J Occup Health Psychol 1999;4:245-55.

43 AFA insurance. Accidents and sick-leave in retail and restaurants (in Swedish). Stockholm: AFA försäkring, 2017.

44 Statistics Sweden. Grundtabeller AKU, 15-74 år, årsmedeltal enligt internationell definition, 2019. Available: https://www.scb.se/hittastatistik/statistik-efter-amne/arbetsmarknad/arbetskraftsundersok ningar/arbetskraftsundersokningarna-aku/pong/tabell-och-diagram/ icke-sasongrensade-data/grundtabeller-aku-1574-ar-ar/

45 Balogh I, Ohlsson K, Nordander C, et al. The importance of work organization on workload and musculoskeletal health - grocery store work as a model. Appl Ergon 2016;53:143-51.

46 Johansson K, Lundgren AS. Gendering boundary work: exploring excluded spaces in supermarket job rotation. Gender Place Cult 2015;22:188-204.

47 Marklund S, Berntson E, Bolin M, et al. Changing organisations and work-related health: Technical report of methods, sample and design of three studies. Stockholm: Arbetslivsinstitutet, 2006: 47.

48 Berthelsen H, Hakanen JJ, Westerlund H. Copenhagen Psychosocial Questionnaire - A validation study using the Job Demand-Resources model. PLoS One 2018;13:e0196450.

49 Kuorinka I, Jonsson B, Kilbom A, et al. Standardised Nordic questionnaires for the analysis of musculoskeletal symptoms. Appl Ergon 1987;18:233-7.

50 Bergsten EL, Mathiassen SE, Vingård E. Psychosocial work factors and musculoskeletal pain: a cross-sectional study among Swedish flight baggage handlers. Biomed Res Int 2015;2015:ID 798042.

51 Jahncke H, Hygge S, Mathiassen SE, et al. Variation at work: alternations between physically and mentally demanding tasks in blue-collar occupations. Ergonomics 2017;60:1218-27.

52 Task force of the European Society of cardiology, the North American Society of pacing and electrophysiology. Heart rate variability: standards of measurement, physiological interpretation, and clinical use. Eur Heart J 1996;93:1043-65.

53 Trask C, Mathiassen SE, Rostami M. Partly visible periods in posture observation from video: prevalence and effect on summary estimates of postures in the job. Appl Ergon 2015;49:63-9.

54 Acker J. Inequality regimes: gender, class and race in organizations. Gender \& Society 2006;20:442-64.

55 Acker J. Class questions. Feminist answers. Lanham: Rowman \& Littlefield, 2006.
56 Acker J. Gendered organizations and intersectionality: problems and possibilities. Equal Div and Incl: An Int J 2012;31:214-24.

57 Fielding N, Thomas H. Qualitative Interviewing.. In: Gilbert N, ed. Researching social life. London: Sage, 2001: 245-65.

58 Strauss A, Corbin J. Basics of Qualitative Research. Techniques and Procedures for Developing Grounded Theory. Thousands Oaks: SAGE Publications Ltd, 1998.

59 Miles MB, Huberman AM. Qualitative Data Analysis: An Expanded Sourcebook. Thousands Oaks: SAGE Publications Ltd, 1994.

60 Skotte J, Korshøj M, Kristiansen J, et al. Detection of physical activity types using triaxial accelerometers. J Phys Act Health 2014;11:76-84.

61 Stemland I, Ingebrigtsen J, Christiansen CS, et al. Validity of the Acti4 method for detection of physical activity types in freeliving settings: comparison with video analysis. Ergonomics 2015;58:953-65.

62 Korshøj M, Skotte JH, Christiansen CS, et al. Validity of the Acti4 software using ActiGraph GT3X+accelerometer for recording of arm and upper body inclination in simulated work tasks. Ergonomics 2014;57:247-53.

63 Wahlström J, Bergsten E, Trask C, et al. Full-shift trunk and upper arm postures and movements among aircraft baggage handlers. Ann Occup Hyg 2016;60:977-90.

64 Wahlström J, Mathiassen SE, Liv P, et al. Upper arm postures and movements in female hairdressers across four full working days. Ann Occup Hyg 2010;54:584-94.

65 Heiden M, Zetterberg C, Mathiassen SE. Trunk and upper arm postures in paper mill work. Appl Ergon 2019;76:90-6.

66 Gupta N, Mathiassen SE, Mateu-Figueras G, et al. A comparison of standard and compositional data analysis in studies addressing group differences in sedentary behavior and physical activity. Int $J$ Behav Nutr Phys Act 2018;15:53.

67 Benke G, Sim M, Fritschi L, et al. Beyond the job exposure matrix (JEM): the task exposure matrix (TEM). Ann Occup Hyg 2000;44:475-82.

68 Svendsen SW, Mathiassen SE, Bonde JP. Task based exposure assessment in ergonomic epidemiology: a study of upper arm elevation in the jobs of machinists, CAR mechanics, and house painters. Occup Environ Med 2005;62:18-27.

69 Mathiassen SE, Nordander C, Svendsen SW, et al. Task-based estimation of mechanical job exposure in occupational groups. Scand J Work Environ Health 2005;31:138-51.

70 Searle SR, Casella G, McCulloch CE. Variance components. Hoboken: John Wiley \& Sons, 2006.

71 Mathiassen SE, Jackson JA, Punnett L. Statistical performance of observational work sampling for assessment of categorical exposure variables: a simulation approach illustrated using path data. Ann Occup Hyg 2014;58:294-316.

72 Wasserstein RL, Schirm AL, Lazar NA. Moving to a world beyond " $p<0.05 "$. Am Stat 2019;73:sup1:1-19.

73 Cumming G. The new statistics: why and how. Psychol Sci 2014;25:7-29.

74 Lakens D. Calculating and reporting effect sizes to facilitate cumulative science: a practical primer for t-tests and ANOVAs. Front Psychol 2013;4:863.

75 Heiden M, Garza J, Trask C, et al. Predicting directly measured trunk and upper arm postures in paper mill work from administrative data, workers' ratings and posture observations. Ann Work Expo Health 2017;61:207-17.

76 Mathiassen SE, Paquet V. The ability of limited exposure sampling to detect effects of interventions that reduce the occurrence of pronounced trunk inclination. Appl Ergon 2010;41:295-304.

77 Liv P, Mathiassen SE, Svendsen SW. Theoretical and empirical efficiency of sampling strategies for estimating upper arm elevation. Ann Occup Hyg 2011;55:436-49.

78 Coenen P, Mathiassen SE, Kingma I, et al. Bias and power in group-based epidemiologic studies of low-back pain exposure and outcome - effects of study size and exposure measurement efforts. Ann Occup Hyg 2015;59:439-54. 